\title{
La «Batalla» de Washington La Guerra Civil Española en los Estados Unidos
}

\author{
The «battle» of Washington. Spain/US diplomatic \\ relations during the war
}

\author{
Juan Carlos Merino Morales*
}

\section{Resumen:}

Con el inicio de la guerra civil española se abrieron en el mundo diversos frentes de batalla que iban más allá de los que se producían en territorio patrio. Muchos de estos frentes eran más fuertes que las armas, y cambiar o modificar la legislación de un país era una tarea muy complicada. Este trabajo pretende mostrar la lucha que llevó a cabo el embajador de España en Washington para derogar la Ley de Neutralidad estadounidense que impedía la compra de armas para el gobierno republicano. Para ello se examinan fuentes tantos españolas como norteamericanas que aportarán una visión global del conflicto desde la perspectiva del embajador De los Ríos y de la administración Roosevelt.

Palabras clave: España, guerra civil, Fernando de los Ríos, diplomacia, Estados Unidos, Ley de Neutralidad.

\section{Abstract:}

With the start of the Spanish civil war various war fronts opened fronts opened in the world that went beyond those in the homeland. Many of these fronts were stronger than weapons, and changing or amending legislation of a country was a very complicated task. This paper aims to

Profesor, Universidad Autónoma de Madrid, España. jcmerino@gmail.com Recibido el 14 de agosto de 2013, aceptado el 6 de septiembre de 2013 
show the struggle of the Spanish ambassador in Washington to obtain the repeal of the United States Neutrality Act that prevented the purchase of arms for the Republican government. This is don examining many Spanish and American sources, that provide an overview of the conflict from the perspectives of Ambassador De los Rios and the Roosevelt administration.

KeYwords: Spain, civil war, Fernando de los Ríos, diplomacy, United States, Neutrality Act. 
Juan Carlos Merino Morales • La «batalla» de Washington. La guerra civil española...

In the United States an avalanche of isolationism was over-whelming any prospect of inducing the American people to agree to a more vital share in world affairs. Congress, having disavowed the World Court, was seeking ways to legislate us out of possible involvement in the next war, which was becoming more and more inevitable.

Cordell Hull

\section{LA NEUTRALIDAD COMO VÍA DIPLOMÁTICA}

\section{Los inicios}

Después de la I Guerra Mundial, Estados Unidos desarrolló su economía y sociedad de tal forma que se terminó llamando a la década los felices años 20. Todo iba sobre ruedas: se producía, se consumía, aumentaban los salarios y parecía que aquel gran país no iba a encontrar fin a su crecimiento. $Y$ así fue hasta la gran crisis del 29, que hizo que esa sociedad próspera que se sentía invencible e irreductible replantear muchas cosas. Los años de bonanza hicieron que los problemas o bien no se viesen o no se quisieran ver. Pero aquel «jueves negro» de finales de la década provocó no solo que un país cayera en la ruina, sino que empezaran a plantearse cuestiones que la prosperidad simplemente había dejado de lado. Y es que hasta dieciséis años después de la entrada de Estados Unidos en la "gran guerra", no se empezaron a analizar seriamente las razones que movieron a Wilson a entrar en ella. Para ello se creó en el Senado el Special Committee on Investigation of the Munitions Industry, a cuyo cargo estaba el senador Nye, de ahí que se acabase llamando Comité Nye. Gerald P. Nye, senador por Dakota del Norte, se puso al frente del comité tras ser designado por la mayoría demócrata del Senado y contó con la colaboración de otros seis miembros entre los que estaban Homer T. Bone, Warren Barbour y Arthur H. Vanderberg. Además, como jefe de la investigación actuó Stephen Raushenbush.

El comité se creó tras la elaboración de numerosos informes que demostraban que, en buena medida, entró Estados Unidos en la I Guerra Mundial, debido a la presión ejercida en el gobierno para la industria armamentística estadounidense. Según datos del propio gobierno, en la guerra del 14 perecieron más de 53 mil soldados. La creciente tensión que se vivía en Europa en la primera mitad de la década de los años treinta hizo que se buscara una legislación que mantuviera el tradicional aislacionismo de los Estados Unidos. El comité partía de la negativa rotunda de su presidente, el senador Nye a participar en cualquier guerra extranjera sin obviar, claro, el asunto armamentístico. Asimismo al comenzar la investigación advertía: "cuando la investigación del Senado haya terminado veremos que la guerra y la preparación para la guerra no es una cuestión de honor nacional ni de defensa nacional, sino una cuestión de beneficio para unos pocos».

El comité estuvo trabajando dieciocho meses a partir del 4 de septiembre 
de 1934 tras pasar todo el verano analizando la documentación que tenían en un primer momento. En ese año y medio se celebraron noventa y tres audiencias y se interrogaron a más de 200 testigos, entre los que destacan personajes tan relevantes de la sociedad estadounidense como el banquero J.P. Morgan Jr. o Pierre du Pont de la General Motors. De esta forma la investigación se centró en la industria armamentística, las ofertas de contrato de las empresas armadoras de barcos, los beneficios generados por la I Guerra Mundial y los motivos reales por los que Estados Unidos entró en la "gran guerra».

El comité contó con el apoyo del Presidente y del Secretario de Estado y puso énfasis en lo relacionado al tráfico de armas $^{1}$. Aunque la colaboración obtenida fue total, el comité fue un quebradero de cabeza para Cordell Hull. Debido a las quejas que recibió de otros países como Argentina o Gran Bretaña. En su labor, era habitual que el comité buscase contrastar contratos y acuerdos con otros países por lo que estos se sentían "atacados» y elevaban sus quejas a la Secretaría de Estado. En este sentido, cabría destacar la reunión que celebró con Nye a mediados de septiembre cuando le habló del peligro que tenían las investigaciones sobre las relaciones exteriores de los Estados Unidos. Además la opinión que el mismo Hull tenía sobre el comité, XXXXX de aislacionista, debido a que las pesquisas

Hull, Cordell (1948), The Memoirs of Cordell Hull, Nueva York: MacMillan Company, vol. 1, p. 398. giraban en torno a la idea de que la paz que se quería alcanzar era para Estados Unidos. Una paz que podía conseguirse sin atender a los conflictos exteriores, y declarándose neutral en todas las disputas que pudieran surgir. Esta idea estaba muy presente en la clase política estadounidense y no encontró ninguna oposición en ningún estamento.

Las leyes de neutralidad tuvieron como función principal prohibir todo tipo de comercio de carácter armamentístico con cualquier país que participara en una guerra. En un primer momento el Presidente Roosevelt vio con buenos ojos esta normativa, ya que a finales del mes de agosto del año 1935, Italia se disponía a atacar Etiopía. Con la esencia de la ley, el mayor perjudicado en este sentido iba a ser Italia por ser un país superior, que tenía que transportar materiales y contingentes de guerra hacia el país africano y que tenía mayor capacidad adquisitiva. Un año más tarde, se prorrogó la ley en las mismas condiciones, que no se verían alteradas hasta el inicio de la guerra civil española ${ }^{2}$.

2 Para obtener mayor información de recomienda la lectura de:

Duroselle, Jean Baptiste (1965), La política exterior de los Estados Unidos. De Wilson a Roosevelt (1913-1945), México: Fondo de Cultura Económica.

Dallek, Robert (1999), Franklin D. Roosevelt, Nueva York: Oxford University Press.

Hull, Cordell (1948) op. cit. vol. 1, pp. 397-417. 
Juan Carlos Merino Morales • La «batalla» de Washington. La guerra civil española...

i 8 de Julio en Fuenterrabía, WASHINGTON Y LA MORAL

En plena campaña electoral se encontraba Franklin D. Roosevelt cuando le llegaron las primeras noticas del levantamiento armado que se estaba produciendo en España. Las noticias que le llegaban eran confusas en un primer momento. El Presidente no se preocupó en exceso y cedió toda la gestión del conflicto a Cordell Hull.

Desde un punto de vista político la posición aislacionista de los Estados Unidos estaba protegida por la legislación ya analizada. Ninguno de los miembros de la clase política estadounidense había reparado en la posibilidad de un enfrentamiento bélico dentro de un mismo país. Es así que cuando estalló la guerra civil española no había ningún impedimento legal para adquirir armas en el territorio estadounidense.

Ante esta situación el Departamento de Estado no quiso alejarse ni un milímetro de la línea de su política exterior. Durante los primeros días reinó la expectación y la cautela, esperando que el gobierno republicano pudiera encauzar la situación generada por los militares rebeldes aun yendo en contra de las informaciones que recibía el embajador Bowers desde Madrid. Cabe aclarar que en el momento en el que la guerra estalló, Bowers estaba de vacaciones con su familia en Guipúzcoa, y que a cargo de la embajada se quedó su segundo, Hallet Johnson, quien le informaba puntualmente de la situación que se vivía en la capital. En una de sus informaciones, el ayudante del embajador anunciaba que el gobierno republicano había optado por repartir armas entre la clase trabajadora ${ }^{3}$. Pero esta no era la única información que recibía Bowers, ya que en un tono más agresivo su encargado de asuntos exteriores, Eric Wendelin, escribía que los comunistas y los socialistas estaban cometiendo actos de depredación ${ }^{4}$.

La primera acción que ordenó Cordell Hull el 22 de julio fue la repatriación inmediata de los ciudadanos estadounidenses. Ésta se desarrolló sin ningún problema y junto con el progresivo restablecimiento del orden por parte del gobierno, se empezaron a barajar las distintas opciones que tenía el Departamento de Estado y el propio Roosevelt tenían encima de la mesa. En esta tarea participó de forma activa el embajador Bowers una vez estuvo instalado en San Juan de la Luz, y a través de un destructor, el Cayuga, fue recogiendo estadounidenses de diversos puertos del Cantábrico, como Bilbao o Gijón ${ }^{5}$.

Mientras tanto Hull buscaba asesoramiento militar y lo encontró en el almirante William H. Stanley, jefe de las operaciones navales de la Marina de los Estados Unidos ${ }^{6}$. De las reuniones

3 Little, Douglas (1985), Malevolent Neutrality: The United States, Great Britain, and the Origins of the Spanish Civil War, Ann Arbor: Cornell University Press, pp. 223.

4 Ibid.

5 Bowers, Claude (1977) Misión en España, Barcelona: Grijalbo, pp. 264-270.

6 Little, Douglas (1985), op. cit., pp. 224. 
que mantuvieron se sacó en claro que el reparto de armas al pueblo había sido un error, ya que no disponían de la formación militar necesaria y eso les hacía más débiles frente a los rebeldes, bien preparados en las largas campañas africanas.

Pero el terreno militar no era el punto que más preocupaba a la administración Roosevelt, sino los intereses económicos estadounidenses en España, especialmente sus dos grandes empresas de automoción, General Motors y Ford en PobleNou, cuyas factorías fueron expropiadas y colectivizadas, para guiar su producción a fines bélicos, aunque más tarde, al ir avanzando los rebeldes, acabaron por vender a estos sus productos ${ }^{7}$.

Al mismo tiempo, en Washington Hull discutía con el subsecretario de Estado, William Phillips, sobre el papel que estaba teniendo Italia en los primeros momentos de la guerra. Las informaciones que manejaban eran que Mussolini estaba mandando material militar. Se valoraron las repercusiones que esta asistencia podía tener en la contienda española. Estas noticias se cruzaban con las que llegaban desde Moscú y la afinidad comunista que según ellos estaba tomando el gobierno del Frente Popular en Madrid, con la incursión de comunistas y radicales en los mandos gubernamentales. En este sentido, Phillips consideró las posibili-

Tierney, Dominic (2007), FDR and the Spanish Civil War, Duke: Duke University Press, p. 84. dades de enviar armamento a un bando, a otro, a los dos o a ninguno ${ }^{8}$.

El propio Phillips era el mayor aliado que tenía el gobierno republicano en los Estados Unidos y fue el que defendió un mayor compromiso con los leales y la posible ayuda a estos 9 . El problema con el que se encontró era la tradición aislacionista de los estadounidenses y el miedo a entrar en una nueva guerra que se desarrollaba a más de cinco mil kilómetros. Pero la pequeña resistencia que podía representar Phillips se desvaneció cuando cesó de sus funciones en el Departamento de Estado a finales de agosto, cuando se le nombró embajador en Italia.

En ese momento el Senado presionaba al Presidente para que proclamase la neutralidad de los Estados Unidos en la guerra civil española. Ideológicamente Franklin D. Roosevelt simpatizaba con el gobierno republicano, pero a la hora de valorar el enfrentamiento desde un punto de vista político, la posible victoria rebelde del general Franco no le suponía ningún problema, y para ello consideró que la política de neutralidad era el mecanismo idóneo para controlar la guerra desde la propia Europa. Es por este motivo por el que se empezó a gestar una ampliación de la ley de neutralidad. El 4 de agosto y con Hull y el aún subsecretario Phillips, empezaron las discusiones sobre cómo habría que actuar.

Hull, Cordell (1948), op. cit., vol. 1, p. 404.

9 Tierney, Dominic (2007), op cit., p. 41. 
Juan Carlos Merino Morales • La «batalla» de Washington. La guerra civil española...

Las anteriores leyes de neutralidad se estipularon ante la idea de no dar ningún tipo de cobertura a países que en ese momento se encontraran en guerra. Sin embargo no había ningún tipo de legislación que impidiese vender armas a un país que se encontrara en situación de guerra interna, hecho que dejaba a la guerra civil española fuera de estas limitaciones.

Además, se tomaron en consideración los diversos frentes que se podrían abrir si cualquiera de los dos bandos vencía. De este modo, se valoró una posible victoria del gobierno legítimo de la República y se consideró esta posibilidad como un impulso para los comunistas de Europa. En este sentido, Loy Henderson, encargado de Asuntos Exteriores de Estados Unidos en Moscú, confirmó a la Secretaría de Estado que el gobierno de Stalin había empezado a proveer al gobierno de Giral de armamento diverso ${ }^{10}$. Mientras tanto Francia decidió no suministrar armas a ningún bando, empezando así en un primer momento la política de no intervención contra la que luchó en todo momento la escuálida diplomacia republicana.

A partir de este momento corrió como la pólvora la unión de comunismo y república y hasta algunos funcionarios estadounidenses en España, como el cónsul en Málaga, empezaron a llamar a los leales al gobierno republicano «rojos», igual que hacían los sublevados ${ }^{11}$. En este sentido cabría

10 Little, Douglas (1985), op cit., p.234.

11 Ibid.. destacar las palabras del teniente Hutt, quien reiteró que «Rusia está formando y organizando a los obreros [...], que los obreros han probado la sangre de los rebeldes, [...] y que si el Frente Popular ganaba, la situación en España sería como la de Rusia en 1917, mientras que una victoria de los rebeldes crearía un gobierno fuerte» ${ }^{12}$.

Ante estas informaciones la no intervención se iba asentando en la mente de los responsables de la diplomacia estadounidense. En este sentido, Roosevelt tenía sus dudas según informaciones de su hijo Elliott, pero finalmente optó por liderar la campaña por la no intervención en España ${ }^{13}$.

Pero los responsables de la compra de armas por parte de la República no estaban quietos y ya en esos primeros días de agosto habían contactado a distintas empresas estadounidenses para comprar aviones. Una de estas empresas fue la que aceleró la posición en firme del gobierno de Roosevelt. Fue la empresa de Ohio, Glenn L. Martin Company, la que preguntó al Departamento de Estado sobre la venta de ocho aviones al ejército leal español, y ante esto el subsecretario Phillips vio la posibilidad de marcar el camino a seguir en relación con el conflicto español ${ }^{14}$. Para ello tuvo conversaciones tanto con el presidente como con Hull y entre ellos y con el conjunto de responsables en política exterior de Estados Unidos debatieron la mejor forma de proceder para los intereses de su

12 Hull, Cordell (1948) op cit., vol. 1, p. 405.

13 Tierney, Dominic (2007) op. cit., p. 45.

14 Little, Douglas (1985) op. cit., p. 235. 
país. Finalmente, el gobierno contestó a la empresa armamentística, que la venta de armas a terceros países no iba con el espíritu del gobierno y por ese motivo no querían que la venta tuviese lugar. Este tipo de negociaciones acabaron con un nombre que marcaría las relaciones con España durante los meses que le quedaban a aquel año 1936, y que tomaría el nombre de embargo moral.

Este fue el medio por el que el Departamento de Estado instó a las empresas armamentísticas a que no realizaran ninguna venta a cualquiera de los dos bandos por su propia iniciativa sin la necesidad de ampliar la legislación de neutralidad vigente en ese momento. El principal valedor fue el propio secretario de Estado, mientras que entre los detractores se encontraba el asistente del propio Hull, Robert Walton Moore, o como reconoció Sumner Welles más tarde, muchos oficiales habían cuestionado en esos tensos días la estrategia del embargo moral. Quien sí puso voz firme en contra fue Joseph C. Green, jefe de la oficina de control de armas y munición, quien alegó que el embargo podía dejar al Departamento de Estado en una situación de debilidad en el caso de que se produjese un conflicto en América Latina y el gobierno legítimo pidiese ayuda para detener la insurgencia, como ya había sucedido $^{15}$. Oficialmente el embargo moral comenzó el 11 de agosto de 1936 dando el pistoletazo de salida a la no intervención, ya que tan solo cuatro

15 Little, Douglas (1985) op. cit., p. 237. días más tarde ${ }^{16}$. Inglaterra aceptó la proposición de neutralidad de Francia.

En los meses siguientes, hasta enero de 1937, el embargo moral frenó todos los intentos de adquisición de armas para la guerra civil española. Además, había que tener en cuenta el respaldo que esta medida tenía en la sociedad estadounidense, ya que en los primeros días de agosto la inmensa mayoría de la población, apoyaba las restricciones armamentísticas impuestas por su gobierno, como garantía de exclusión de su país en cualquier conflicto armado.

\section{De lo MORAL A LA}

\section{NEUTRALIDAD}

Durante el final del verano y en el otoño siguiente, las directrices impartidas por la Secretaría de Estado fueron cumplidas de forma severa por las empresas norteamericanas. Todo se truncó a finales del mes de diciembre cuando apareció en escena el nombre de Robert Cuse.

Vimalert Co. era una empresa estadounidense dedicada a la venta de aviones de segunda mano, cuyo presidente era Robert Cuse. De origen lituano llegó a las portadas de los periódicos cuando se atrevió a plantarle cara al Departamento de Estado y romper el embargo moral que estableció la administración Roosevelt. Como no había legislación que limitase la venta de armas, Cuse pidió la licencia el 24 de diciembre y pocos días más tarde la

16 Ibíd. 
Juan Carlos Merino Morales • La «batalla» de Washington. La guerra civil española...

obtuvo para vender al gobierno republicano diferentes aviones ${ }^{17}$. El precio final de la venta así como de la cantidad de aviones, armas y demás material armamentístico es difuso; unas fuentes citan 2.777.000 dólares ${ }^{18}$ mientras que otras cifran entre millón y medio y dos millones de dólares ${ }^{19}$.

En un primer momento se podría valorar esta compra como un beneficio para la República y una gran gestión del aparato diplomático, pero el efecto que tuvo sobre el gobierno legítimo fue devastador. Para Roosevelt este intento de saltarse las normas no escritas fue considerado como antipatriótico. Asimismo anunció que tan pronto como el Congreso se reuniese habría dado a España su aprobación para ampliar la legislación sobre neutralidad. La primera semana de enero del nuevo año, comenzaron las gestiones en el Congreso y para ello las cámaras legislativas contaron con dos personas muy importantes que trabajaron y detallaron la ley de neutralidad que en esos momentos estaba a punto de ampliarse. El senador Pittman, como jefe de la oficina de asuntos exteriores del Senado y el congresista McReynolds, su homólogo de la Cámara de Representantes presentaron diferentes propuestas de ampliación de la ley de neutralidad a sus respectivas cámaras. Ambas propuestas eran firmes y contemplaban la prohibición expresa

17 Rey, Marta (1997), Star for Spain. La Guerra civil española en los Estados Unidos, A Coruña: Edicios do Castro, p. 29. 18 Ibíd.

19 New York Times, 31 de diciembre de 1936. de enviar material de guerra, armas y munición a España.

Mientras tanto pareció que se había abierto la veda y las peticiones de licencias de exportación de armas a España en los primero días de enero, empezaron a llegar por lo que el Congreso, Hull y el mismo Roosevelt se apresuraron en sacar adelante la ampliación de la ley de neutralidad. El día seis de enero fue clave ya que los poderes ejecutivo y legislativos de los Estados Unidos presentaron sus propuestas sobre la ley. El Presidente Roosevelt, en su mensaje anual al Congreso, pidió a sus compañeros que buscaran la mejor forma de actuar con España, para lo cual había que ampliar la legislación sobre neutralidad. Inmediatamente después se aprobaron las cláusulas en las que había más puntos de encuentro entre los congresistas. Según escribe Hull en sus memorias, el Congreso no creía que la ley de neutralidad ayudara a Franco ${ }^{20}$. Entonces, lo que se plantea es en qué quedaban las informaciones que tenía el Departamento de Estado o que el mismo embajador de Estados Unidos en España había enviado sobre la ayuda alemana e italiana en el verano de 1936, como ya se ha comentado.

Pero todo fue muy rápido, siendo uno de los motivos el zarpe de Nueva York del Mar Cantábrico con las armas de Cuse rumbo a España. Es por esto que el día 8 de enero, tan solo dos días después del llamamiento que hizo Roosevelt, la Cámara de Representantes

20 Hull, Cordell (1948), op. cit., vol. 1, p. 505. 
aprobó por una inmensa mayoría de 411 votos a favor y solo uno en contra la Neutrality Act of 1937. A partir de ese momento comenzaría a aplicarse como medida de emergencia a través de la Joint Resolution, con vigencia limitada en el tiempo, ya que no se trataba de una ley nueva sino de la ampliación de la ley de neutralidad del año anterior, por lo que entraría en vigor a partir del 1 de mayo de 1937.

Aun así, la actividad en el Congreso en este tema no se detuvo. Ambas cámaras siguiendo negociando, aprobando y rechazando enmiendas. Es el caso de la que propuso Pittman en el Senado el 22 de enero, por la que buscaba dar más poder al Presidente Roosevelt en este aspecto para que, según su criterio, pudiera suspender, ampliar o derogar la ley. El Presidente también quería que la resolución incluyera una disposición en virtud de la cual, si se comprobara que el material de guerra estadounidense, con destino a un país neutral, había sido distribuido a un bando beligerante, se pudiera actuar en consecuencia y se le autorizara para confiscar los bienes del fabricante los Estados Unidos. Además, se entregó tanto a Moore como al asesor legal Hackworth, un memorando sobre las medidas de represalia que podían aplicarse para disuadir a toda empresa estadounidense de participar en la guerra, ya que este era lo que quería cortar las leyes de neutralidad. Finalmente tras más de un mes de debate, la resolución se aprobó el tres de marzo por 63 votos a 6 . Por su parte la similar que presentó McReynolds en la Cámara de Representantes se aprobó por 372votos contra $12^{21}$.

Para que la ley fuera completa y no hubiese problemas en el futuro, la Oficina de Control de Armas y Municiones encabezada por Joseph Green, preparó un informe en el que se barajaban los posibles efectos de la ley y si esta podría aplicarse a los dos países de que estaban ayudando a los rebeldes. Alemania e Italia, llegaron a la conclusión de que estos eran mínimos, porque la venta de armas a ambos era casi insignificante y ampliar la legislación sobre estos no serviría de nada ${ }^{22}$.

Así se llegó a mayo de 1937, cuando se aprobó finalmente la Ley de Neutralidad, aún con los ecos de las bombas de Guernica, que tanto escandalizaron a la opinión pública pero que de nada sirvieron para que el Congreso, el Presidente Roosevelt o su Departamento de Estado pensaran en derogarla.

\section{LA EMBAJADA COMO FRENTE}

Llegados a este punto el lector/a podrá preguntarse si el gobierno republicano no hizo nada para frenar o impedir este proceso. Está claro que el golpe de estado provocó al menos que los cimientos diplomáticos españoles, tambalearan. La Embajada de España

21 Hull, Cordell (1948), op. cit., vol. 1, p. 507.

22 Peace and war, United States foreign policy, 1931-1941. (Washington, U.S. Govt. print. off., 1943), by United States Department of State,: 35-37. [consultado 30 abril de 2013]. 
Juan Carlos Merino Morales • La «batalla» de Washington. La guerra civil española...

en Washington no fue menos. Cuando los rebeldes se levantaron en armas contra la República, Luis Calderón ocupaba el cargo de embajador y en septiembre de 1936 presentó su dimisión por afinidad con los rebeldes ${ }^{23}$.

Con el cambio de gobierno y la llegada de Largo Caballero a la presidencia del Consejo de Ministros se normalizó la situación de la política exterior y se colocaron personajes notables de la política española, como Marcelino Pascua en la Unión Soviética, Pablo de Azcárate en Gran Bretaña y Fernando de los Ríos en Estados Unidos.

De esta forma, De los Ríos cesó de su recién inaugurado puesto como rector de la Universidad Central de Madrid, se preparó para su viaje a Washington y tomar el control de una cancillería clave a lo largo de la guerra civil española ${ }^{24}$.

\section{DE LA BÚSQUEDA DE ARMAS A LA «PELEA» LEGAL.}

Fernando de los Ríos entregó su plácet de embajador al Presidente Roosevelt el ocho de octubre de 1936. A partir de ese momento su trabajo consistió en buscar armamento para el gobierno republicano. Para ello se movió por distintos ambientes y se contactó con posibles vendedores, bien de forma directa, o a través de intermediarios o

23 Bosch, Aurora (2012), Miedo a la democracia. Estados Unidos ante la Segunda República y la guerra civil española, Barcelona: Crítica, p. 122.

24 Gaceta de Madrid, 31 de agosto de 1936. $\mathrm{N}^{\circ}$ 244: 1568. de terceros países. Una cuestión que el nuevo embajador no podía obviar era el embargo moral establecido por lo que para no complicar aún más la situación en los últimos meses de 1936 optó por encontrar aliados en otros países. En esta tarea contó con la inestimable ayuda del embajador francés en Estados Unidos, Georges Bonnet.

Así, en colaboración con otros países, especialmente México, se intentaron compras de material bélico, como la oferta que se hizo a De los Ríos, para la compra de veinte aviones Bellanca, así como ametralladoras, bombas y demás armamento $^{25}$. Con esta y con otras opciones de compra se llegó hasta finales de diciembre cuando el ya mencionado Robert Cuse levantó todas las tempestades habidas y por haber en el Departamento de Estado y cuyas reacciones trasladó De los Ríos al Ministerio de Estado el 29 de diciembre ${ }^{26}$.

Los acontecimientos a partir de este momento ya han sido analizados y cabe destacar que se entraba en un terreno en que Fernando de los Ríos se sentía más cómodo, es decir, el ámbito político y no el armamentístico, como señaló el propio De los Ríos durante su estancia junto con Pablo de Azcárate en la Embajada de España en París, días después del golpe de Estado. Ninguno de los dos tenía experiencia en la compra de armas, ni siquiera en la negociación y De los Ríos llegó a desconfiar de toda

25 Telegramas 158 y 159, ARE.FFR. Caja 25, carpeta 1, documento 13 .

26 Telegrama 220,ARE.FFR. Caja 25, carpeta 1 , documento 30 . 
persona que acudía a la Embajada ofreciendo armas, ya que no sabía si eran personas legales o simples estafadores.

Volviendo a la mera cuestión política, una vez aprobada la ley en el Congreso, De los Ríos empezó a tener encuentros con diferentes personalidades. En este sentido se volvió a apoyar en el embajador francés Bonnet y también en Walter Runciman, ayudante del embajador británico, Ronald Lind$\operatorname{say}^{27}$. Incluso actuando en contra de las directrices de sus gobiernos, entre ellos delinearon estrategias paralelas para hacer ver tanto a Hull como a Roosevelt la necesidad si no del apoyo al gobierno republicano, de neutralidad real y de denunciar en instancias nacionales e internacionales las agresiones que la población civil española estaba sufriendo por parte de los rebeldes con la innegable ayuda de alemanes e italianos. En este sentido, lo que le pedían al Departamento de Estado era que los Estados Unidos exigiesen que se cumpliera la normativa internacional, así como los acuerdos del Comité de No Intervención, que claramente estaba siendo violada por Alemania e Italia. Esta estrategia se puede comprobar en la reunión que mantuvieron Roosevelt y Bonnet en el mes de abril. En este encuentro el embajador francés pidió al Presidente que no hablase de una guerra civil en España, sino de una guerra de invasión, ya que la clara participación de los países ya citados en la ayuda y apoyo a los sublevados

27 Telegrama 45,ARE.FFR. Caja 25, carpeta 2, documento 12 . podía considerarse un enfrentamiento civil. En su reclamación, pidió que la Ley de Neutralidad se ampliara tanto a Italia como a Alemania y Portugal, que aunque en este último caso no daba apoyo militar, sí lo daba logístico ${ }^{28}$. Era tal la ayuda prestada por Bonnet a De los Ríos le envío un informe detallado de la reunión, en que Roosevelt le había propuesto diferentes caminos para llegar a la paz en España ${ }^{29}$. La propuesta de Roosevelt indicó que lo óptimo sería celebrar una conferencia de desarme. El problema sería sin duda que ni Inglaterra, ni Alemania ni Italia acudirían a ella, por lo que no tendría sentido celebrarla. Esto se debería a que a Roosevelt le constaba que Inglaterra ya estaba comerciando con Franco y además era algo notorio que el gobierno británico no simpatizaba con el gobierno fretepopulista. La compra no violaba la no intervención, ya que habían adquirido pirita de las minas controladas por los rebeldes. El Presidente sabía este hecho, ya que hasta ese momento quien proveía a Inglaterra eran los propios Estados Unidos.

Esta estrategia de concienciación internacional fue la que siguió Fernando de los Ríos y para ello siguió diversos caminos. Por un lado la vía política, refrendada el quince de marzo de 1937, cuando en una reunión con Cordell Hull le presentó datos de la intervención de Alemania e Italia en España

28 Telegrama 128, ARE.FFR. Caja 25, carpeta 2, documento 50 .

29 Telegrama 153, ARE.FFR. Caja 25, carpeta 2, documento 63 . 
Juan Carlos Merino Morales • La «batalla» de Washington. La guerra civil española...

después de la cual dirigió un mensaje por radio, en el que alegó que Italia había entrado en guerra con España sin declaración formal, ya que en ese mismo momento, unidades italianas luchaban contra el gobierno legítimo de la República, por lo que se estaba violando de forma inexcusable el Pacto de No Intervención ${ }^{30}$. Además de forma indirecta realizó una crítica a los organismos internacionales por ignorar las violaciones que se estaban cometiendo en suelo español. Es por esto que hizo un llamamiento al conjunto de la sociedad internacional para que atendiera a razones de justicia y equidad entre los pueblos, de modo que todos aquellos que en esos momentos hacían caso omiso de las reglas establecidas en el Pacto Briand-Kellogg, fuesen considerados «enemigos de la paz» por el resto de la comunidad internacional.

Conforme avanzaban los días de la primavera de 1937, De los Ríos intensificó su trabajo y sus contactos con los miembros de la Cámara de Representantes. El 1 de abril sostuvo la primera reunión con un grupo afín a la República en la que se acordó comenzar una campaña de presión hacia la clase política estadounidense. Asimismo, tuvo reuniones con distintos congresistas.

Paradójicamente en los últimos y difíciles días de abril se abrió un halo de esperanza El día 26 y siguientes las poblaciones de Guernica y Durango, fueron objeto de terribles bombardeos

30 Telegrama 95, ARE.FFR. Caja 25, carpeta 2, documento 34. ARE.FFR. de la aviación alemana que arrasaron estas poblaciones vascas. El impacto en la sociedad estadounidense fue claro y patente como recogieron diversos periódicos como el New York Times, el Washington Post o el New York Herald $^{31}$.

Pero todo este trabajo para frenar la legislación que prohibiría la compra de armas no fue suficiente y el 1 de mayo de 1937 se aprobó la Ley de Neutralidad, que oficializaba a la Joint Resolution de enero, empezando así de forma oficial el embargo.

Este revés provocó, como se podía suponer, un punto de inflexión en el trabajo del embajador español, sin embargo como hombre con un bagaje político claro y notorio supo adaptarse a su nueva misión, dejar de lado la búsqueda de armas y centrarse en hacer ver a la clase política estadounidense el error cometido al negar «su derecho natural como país que cumple la legislación internacional a comprar armas a un país amigo como lo eran los Estados Unidos $^{32}$.

La primera reunión formal después de que se aprobara la ley se dio entre De los Ríos y Hull el 1 de julio de 1937. Ese día, el embajador español protestó oficialmente sobre la actitud de Alemania en la guerra civil española, acusándola de violar los tratados y acuerdos internacionales. Para ello puso como ejemplo la presencia de barcos

31 New York Times, 30 abril 1937. Washington Post, 28 abril 1937. New York Herald Tribune, 28 abril 1937. 32 Nota manuscrita, ARE.FFR. Sin catalogar. 
alemanes en el puerto de Ibiza, o el bombardeo de Almería el día antes de la reunión. Pero siguiendo con la tónica general impuesta por Hull, De los Ríos se fue de vacío, ya que solo recibió alusiones vagas a la paz y a la estabilidad internacional.

Para la Embajada este tipo de reuniones eran insuficientes e insatisfactorias, por lo que todas las gestiones que se llevaron a cabo se centraron en conseguir una reunión con Roosevelt. Pasaron dos meses antes de que se concertara dicha reunión, hasta que el 14 de septiembre se produjo finalmente el encuentro. Preparando la reunión De los Ríos vio las dificultades que tenía su empresa. Era altamente improbable que la Ley de Neutralidad se derogara pocos meses después de su aprobación por lo que su estrategia que usó fue la de mostrar?? los problemas con que tropezaran los Estados Unidos y el conjunto de los países occidentales si en España triunfaban los rebeldes. Ligó España con Latinoamérica y la posible influencia de un régimen dictatorial en países cercanos a Estados Unidos y con regímenes políticos volátiles, que podían cambiar su tendencia democrática por una fascista ${ }^{33}$. Cabe recordar que este era el temor que había manifestado el Subsecretario Phillips en el debate del Departamento de Estado sobre el embargo moral Pero el miedo al fascismo en el mismo continente no solo fue infundido por De los Ríos sino que varios senadores que poco a

33 Telegrama 309, ARE.FFR. Caja 25, carpeta 2, documento 95 . poco habían empezado a ser afines a la República alertaron de este peligro a la Secretaría de Estado. Lo escabroso de esta situación fue nada más y nada menos la respuesta que dio Hull a los senadores, ya que les dijo que a ellos nos les constaba que Alemania o Italia estuviesen participando en la guerra civil española ${ }^{34}$. A lo largo del presente trabajo y como se puede ver en toda la bibliografía del tema, pocas semanas después del levantamiento militar la Secretaría de Estado sabía que a Franco le estaban ayudando tropas enviadas por Mussolini y Hitler. Aun así, la respuesta de Roosevelt a estas peticiones fue como la de sus subordinados, tibia y exculpatoria.

De todas formas, en ese momento Cordell Hull quería erigir a los Estados Unidos como el defensor de la paz mundial. Es por eso que desde ese mismo verano se dedicó a lanzar mensajes a la comunidad internacional para que esta en su conjunto trabajase de la mano de los Estados Unidos para alcanzar la «paz global» ${ }^{35}$. Este mensaje tenía dos frentes como objetivo, en primer lugar Europa y en particular Alemania e Italia y su clara intervención en España y por otro lado, Japón y China, en pleno inicio de la guerra entre ambos países por el control de la costa oriental del continente asiático. La respuesta por parte del gobierno republicano y en particular del Ministerio de Estado, y

34 Telegrama 213, ARE.FFR. Caja 25, carpeta 2, documento 85 .

35 Varios, AMAEC. Caja RE 135, carpeta 4, pliegos 1-4. 
Juan Carlos Merino Morales • La «batalla» de Washington. La guerra civil española...

que a través de Fernando de los Ríos le hicieron llegar a Cordell Hull y a la Secretaría de Estado que el único objetivo de la República durante la guerra civil era hacer valer la Constitución de 1931, por la que aceptaban «las normas universales del Derecho Internacional», tal como constaba ella ${ }^{36}$. El problema, según señalaba la agencia de noticias Havas fue que, entre otros, Alemania, Italia y Japón no respaldaron esta comunicación ${ }^{37}$.

Conforme pasaron los meses, la opción de derogar o al menos reducir la Ley de Neutralidad iba en aumento. Para ello, Fernando de los Ríos no cesó de presentar pruebas de la presencia de italianos en España. Este fue el caso de la reunión que sostuvo con el Presidente Roosevelt en el mes de octubre. El problema que tuvo fue la barrera infranqueable que imponían tanto el propio Roosevelt como Hull. Su discurso seguía siendo el mismo y el único gesto que De los Ríos pudo sacar de esa reunión fue que mientras Inglaterra y Francia siguieran siendo fieles al Comité de No Intervención y no actuaran contra Alemania e Italia por su presencia en España, ellos no podían hacer nada ${ }^{38}$. Roosevelt le aseguró a De los Ríos que si Francia y sobre todo Inglaterra cambiaban su postura en la

36 Declaración del Gobierno republicano, AMAEC. Caja RE 135, carpeta 4, pliegos 1-4.

37 Informe de la Embajada de España en Estados Unidos, AMAEC. Caja RE 135, carpeta 4, pliegos 1-4.

38 Telegrama 342, ARE.FFR.. Caja 25, carpeta 2, documento 117 . guerra civil española, Estados Unidos se acoplaría al nuevo marco y actuaría en consonancia. Frente a esta posición, la táctica del embajador español fue presionar a los Estados Unidos acusándoles de romper el «Tratado de Amistad y Relaciones Generales entre España y Estados Unidos de América", firmado en el año 1902, bajo el gobierno de Theodore Roosevelt con el de su homónimo Práxedes Mateos Sagasta ${ }^{39}$. Es preciso recordar que con este Tratado, principalmente comercial y marítimo, se restablecieron las relaciones bilaterales entre España y Estados Unidos tras su enfrentamiento en $1898^{40}$.

Poco a poco, De los Ríos fue endureciendo el tono de su discurso con la administración Roosevelt, y como ejemplo se encuentra la larga carta que le envió a Cordell Hull el 19 de noviembre de 1937, donde le recrimina no haber cumplido con la palabra que le había dado en julio, al enumerar los catorce puntos para mantener la paz internacional y a los que el gobierno republicano se adhirió inmediatamente ${ }^{41}$. Como muestra de la carta se encuentra el siguiente párrafo:

«Sin declaración de guerra, sin aviso ni justificación de ninguna clase,

39 Telegrama 349, ARE.FFR.. Caja 25, carpeta 2, documento 120 .

40 Montero, José Antonio (2006), El despliegue de la potencia americana: las relaciones entre España y Estados Unidos, Madrid: Universidad Complutense de $\mathrm{Ma}$ drid, Tesis, p.94.

41 Nota formal 139/04 de Fernando de los Ríos a Cordell Hull, AMAEC. LegajoR1871, expediente 12, pp. 11-15. 
la población civil, incluso mujeres y niños, son asesinados sin piedad por bombas arrojadas desde el aire. --- En tiempos que se llaman de paz, los barcos son atacados y hundidos por submarinos sin causa y sin previo aviso. Algunas naciones fomentan y toman partido en guerras civiles ocurridas en otras que ningún daño les han hecho. Naciones que piden libertad para sí mismas se la niegan otras ${ }^{42}$.

La importancia de la comunicación radica en que De los Ríos pone sobre la mesa las continuas contradicciones de la administración Roosevelt por un lado y por el otro demuestra a todos los detractores que tuvo en su momento que le acusaban de no ser la persona válida para ocupar el puesto de embajador que podía desempeñar perfectamente el cargo para el que fue nombrado. Esta tendencia se dio a lo largo de la guerra civil, como lo revelan diversas cartas enviadas en esos dos años y medio ${ }^{43}$.

Aunque tanto la embajada de España y como el Ministerio de Estado tuvieron distintas posturas frente al Departamento de Estado, el resultado no fue el esperado y la situación no cambiaría hasta enero del año 1938, cuando fue creciendo el apoyo y el reconocimiento de los políticos estadounidenses de todos los colores políticos. El 30 de enero, un total de setenta políticos entre senadores y miembros de

$42 \quad$ Ibidem, p. 12.

43 Por ejemplo, nota formal 139/08, AMAEC. Legajo-R1871, expediente 12, pp.30-35 o extracto de la sección de América y Extremo Oriente del Ministerio de Estado, AMAEC. Legajo-R1871, expediente 12, la Cámara de Representantes, firmaron el siguiente comunicado:

"We, the undersigned members of the Congress of the United States, are happy to send our Greetings and good wishes to the Spanish Parliament on the occasion of it's regular session convened in accordance with the provisions of the Constitution of 1931. For you to meet again in the face of the trying and tragic circumstances of the present demonstrates that the Spanish people and their representative stand firm in their faith in democratic government. We, who cherish freedom and democracy above all else, realize the significance of your heroic and determined fight to save the democratic institutions of your young republic from it's enemies both within and without Spain. Your struggle sets a stirring example to all democratic peoples. As members of one democratic-elected parliament to another, we salute you ${ }^{44}$.

De los Ríos destacó la importancia de este comunicado, ya que estaba firmado por miembros importantes del organigrama de relaciones internacionales de los Estados Unidos y por senadores como Tom Conally, de Texas. Es así como la misión española tomó aire y reforzó su trabajo. Sin embargo, este reconocimiento al gobierno republicano y al trabajo de la Embajada seguía siendo mínimo, ya que en su conjunto no sumaban más del trece por ciento de los miembros del Congreso de los Estados Unidos.

44 Telegrama 21,ARE.FFR. Caja 25, carpeta 3, documento 18 . 
Juan Carlos Merino Morales • La «batalla» de Washington. La guerra civil española...

Este tipo de apoyos fu el que animó tanto al personal de la Embajada como a todas las personas que apoyaban a la República en Estados Unidos. El primer político estadounidense en pedir formalmente la derogación de la Ley de Neutralidad fue el senador demócrata por Utah, William H. King el 8 de febrero de $1938^{45}$. Este suceso hizo que a partir de entonces se prolongaran las reuniones de De los Ríos. Además en esos días de febrero se pudo ver el primer movimiento de Inglaterra y Francia para ayudar a la República. La información le llegó a De los Ríos después de la reunión que mantuvo con el senador King, quien le aseguró que Inglaterra estaba tratando de convencer a Italia y así llegar a un acuerdo para que dejase de prestar ayuda a los sublevados a cambio de importantes sumas de dinero.

En este movimiento de presión hacia la Secretaría de Estado hubo que incluir la información que De los Ríos hizo llegar a Cordell Hull sobre la presencia de más tropas alemanas e italianas en España ${ }^{46}$. En el memorando que le envió mostraba documentación fidedigna de que en el mes de marzo habían llegado a España dos grupos de cuatro escuadrones alemanes con armamento pesado, ciento nueve aviones caza, diecisiete aviones de reconocimiento así como tres baterías de artillería antiaérea. Ante

45 Telegrama 29, ARE.FFR. Caja 25, carpeta 3 , documento 25.

46 Carta de Fernando de los Ríos a Cordell Hull, AMAEC. Legajo-R1871, expediente $12: 16-22$. tan abrumadores datos el Embajador espetó "ipero qué hacen Francia e Inglaterra! ${ }^{47}$.

\section{PRimavera DE I938}

Todos estos movimientos hicieron pensar a De los Ríos y al personal de la Embajada que la posición de los Estados Unidos respecto a la guerra civil iba a cambiar y que finalmente el embargo se levantaría. En la primavera de 1938 se sucedieron los encuentros y las reuniones tanto con Roosevelt como con Hull, pero en ninguna de ellas se consiguió variar el rumbo fijado por ambos. Pero además, viendo que la situación estaba en un momento frágil, De los Ríos pudo entrevistarse con Paul Boncour, Ministro de Asuntos Exteriores de Francia, quien le dijo que Francia solo rompería con el Pacto de No Intervención, si los Estados Unidos accedían a ayudar a la República española ${ }^{48}$. Esto refleja que Estados Unidos aún no quería posicionarse como líder internacional de los países democráticos, siguiendo bajo la línea que le venía marcada tradicionalmente desde Inglaterra, y que Francia, temiendo un enfrentamiento por dos de sus fronteras, no quería actuar sin el apoyo o blindaje de los Estados Unidos. Es decir, era el que en los países democráticos, reinaba el sentimiento de inferioridad

47 Telegrama 79, ARE.FFR. Caja 25, carpeta 3, documento 69.

48 Telegrama 80,ARE.FFR. Caja 25, carpeta 3 , documento 70 . 
o sea por no tener la experiencia que le llevara al liderazgo que se le reclamaba por ser Estados Unidos, o por el contrario, como Francia, porque se sentía débil frente a la agresividad alemana.

Pero De los Ríos siguió con su trabajo, convencido de poder romper todas las barreras que le impedían conseguir su objetivo. Es así que tras volver a entrevistarse con Hull le hizo saber los avances que estaban logrando sus compañeros tanto en Londres como en París, que podrían revertir la situación para que así tanto Inglaterra como Francia y a la postre Estados Unidos, accedieran a ayudar al gobierno legítimo de la República. Entonces De los Ríos recibió un nuevo varapalo por parte de Hull. El Secretario de Estado le dijo que no harían nada al menos hasta que se hubiesen celebrado las elecciones legislativas de noviembre de ese mismo año 1938. Las explicaciones que le dio Hull no fueron otras que de carácter interno. Según él, Roosevelt no se encontraba en una buena posición dentro del Partido Demócrata y esta posición se debilitaría si accedía a inmiscuirse en la guerra civil española, lo que haría enfurecer a los sectores católicos de la sociedad estadounidense, que formaban un férreo apoyo al Presidente.

Este tipo de actitudes hacía que Fernando de los Ríos sintiese que su trabajo no avanzaba. Aun así, no perdió la esperanza. Su trabajo político no estaba teniendo el resultado que quería, pero sin embargo pese a lo cual sus movimientos por distintos sectores de la sociedad estadounidense fueron cuajando y en la presa norteamericana cada vez era más habitual encontrar artículos tanto de información como de opinión favorables a la República española. De esta forma se hizo eco de las informaciones que se aportaban sobre que Roosevelt estaba cediendo a las presiones del senador Nye y que se empezaba a plantear la derogación de la ley debido a que el propio Nye había presentado en la Comisión de Relaciones Exteriores del Senado la moción pertinente ${ }^{49}$.

Pero cuando parecía que las cosas podían cambiar el rumbo, la situación en España se iban complicando por momentos y los ciudadanos españoles salían cada vez más camino del exilio. Este fue el caso de la madre del embajador, por lo que pidió permiso al Ministro del Estado Alvarez del Vayo, para poder ir a recoger a su madre enferma y llevarla con él a Washington. Aun con reticencias, Del Vayo lo autorizó y De los Ríos dejó la Embajada en manos de su encargado de negocios, Enrique de la Casa.

A su vuelta y tras ponerse al corriente de los asuntos de la Embajada, De los Ríos remitió una carta al Ministerio en la que expuso su visión sobre el estado en que se encontraban las negociaciones sobre la Ley de Neutralidad ${ }^{50}$. En la misiva expone los que en su opinión eran muros inexpugnables para el fin

49 Telegramas 108 y 110, AMAEC. LegajoR1008, expediente 3-4, sf.

50 Carta de Fernando de los Ríos a Álvarez del Vayo, AMAEC. Legajo-R1871, expediente 12: 56-62. 
Juan Carlos Merino Morales • La «batalla» de Washington. La guerra civil española...

del embargo. El primero era la Iglesia Católica y la ascendencia que tenía en la sociedad estadounidense y en particular en los votantes del Presidente Roosevelt. Además, como ya se ha citado, 1938 era año de elecciones legislativas y el presidente del comité electoral del Partido Demócrata, James Farly, era un católico confeso y se oponía abiertamente a la derogación de la Ley de Neutralidad. A esta se sumaba la presión diplomática que seguía ejerciendo Inglaterra sobre la Secretaría de Estado. En este sentido, De los Ríos critica abiertamente a Inglaterra, acusando directamente al embajador Lindsay de dificultar su trabajo con el Departamento de Estado. Asimismo, acusa a medios como el Christian Science Monitor o The Nation, de seguir los dictados de Inglaterra y ofrecer una visión completamente contraria a la realidad sobre la guerra civil. En este sentido, argumenta un editorial de The Nation del 28 de mayo de 1938 advertía que si la Ley de Neutralidad se modificaba para favorecer a la República española, los Estados Unidos irían en contra del plan de pacificación inglés ${ }^{51}$.

Políticos como Nye criticaron abiertamente al gobierno por ceder ante Inglaterra. Pero Nye no fue el único, ya que el también senador Borah elevó sus protestas a Roosevelt. Además, otros sectores de la sociedad como fue el caso de escritores que también se opusieron a las presiones inglesas. Cabe destacar el caso del escritor Quincy Howe que

51 The Nation, 28 de mayo de 1938. publicó el libro England expects every American to do his duty., donde se critica abiertamente que la política exterior de Estados Unidos no se decidía en la Casa Blanca sino en el número 10 de Downing Street.

\section{El FinAl DE LA GUERRA}

Después de la primavera, en la Embajada de España la sensación era de desesperación y de derrota. Aunque en su fuero interno sabía que no podrían cambiar la ley, todo el personal siguió trabajando en esa línea. La línea de trabajo se endureció ya que al dar todo por perdido, las formas ya no importaban. Así fue como en el mes de agosto se presentaron tres quejas formales contra la política de Estados Unidos respecto a España. En los peores momentos siempre hay algún rayo de luz que ilumina la esperanza y fue el caso del 22 de agosto, cuando el Presidente Roosevelt pronunció un discurso en que dejaba entrever que la política de aislamiento podía llegar a su fin ${ }^{52}$.

Pero como se preveía, las elecciones legislativas frenaron todo. No se volvieron a tener contactos de importancia para tratar la situación de España hasta diciembre de ese mismo año. $\mathrm{Ni}$ siquiera los acuerdos de Múnich de septiembre hicieron variar un ápice la política estadounidense.

A partir de enero de 1939 con la caída de Barcelona y la guerra perdida,

52 Informe: «El discurso de Roosevelt». AMAEC, Legajo-R1008, expediente 3-4, 
De los Ríos se centró en trabajar por los refugiados y exiliados españoles que salían de España en pésimas condiciones. De Roosevelt y Hull, solo obtuvo la promesa, que finalmente cumplieron, de no reconocer a Franco mientras un gobierno legítimo de España se mantuviera en su territorio.

En los últimos días del mes de marzo, Fernando de los Ríos cedió la Embajada al que sería el nuevo embajador en Washington, Cárdenas, por la mediación de los embajadores de México y Colombia. Esta entrega de poderes fue la constatación de la derrota en «La batalla de Washington».

\section{Conclusiones}

A la hora de llevar a cabo una investigación sobre diplomacia bilateral, el examen de las fuentes de ambos entes políticos además de ser necesario e imprescindible, es enriquecedor. Gracias a ellas se pueden recoger muchas ideas y completar una visión global de la imagen que se tiene del otro. En este sentido las visiones del conflicto se multiplican y la no contrastación puede provocar la confusión. En este caso, a la hora de plasmar los resultados en el papel, se pone de manifiesto la idea que se tenía que Estados Unidos sobre el conflicto español. La mayor parte del tiempo en que Fernando de los Ríos ocupó el cargo de embajador, pensaba, y así lo transmitía al Ministerio de Estado, que la guerra civil era una prioridad dentro de la Secretaría de Estado. Pero como se puede comprobar en las fuentes estadounidenses, desde un punto de vista político España no se contaba entre las prioridades de los asuntos exteriores de los Estados Unidos. Un ejemplo palpable se encuentra en las memorias de Cordell Hull, donde el enfrentamiento bélico español no ocupa ni siquiera un lugar secundario. Sin más, se puede acudir al inicio del capítulo que dedicó a la legislación sobre neutralidad, en el cual España no se refleja entre las inquietudes del Departamento de Estado. Así por ejemplo, en primer lugar el mayor «miedo» lo constituiría Italia seguida de Alemania. Le siguen la tibieza de las políticas exteriores de Gran Bretaña y Francia con los dos primeros, seguida del conflicto chino-japonés y por último, el aislacionismo tradicional de los Estados Unidos en la primera mitad del siglo XX.

Sin embargo, en sus informes y mensajes a España, Fernando de los Ríos exponía, que aunque había grandes barreras para llevar a cabo la principal misión que le llevó a Washington que no era otra que la de comprar armas, sus impresiones eran positivas y confiaba en que, con trabajo, se podrían conseguir dicho armamento. Esta tarea sin duda se puede calificar como fracaso debido a la legislación y al embargo impuesto a España. Aun así, el optimismo patológico del embajador hacía que hasta en los peores momentos pensara que el embargo estaba a punto de levantarse. Solo dejó de pensar así después de volver de recoger a su madre, cuando vio el estado en que se encontraba la población española. Este hecho sin duda le 
Juan Carlos Merino Morales • La «batalla» de Washington. La guerra civil española...

marcó, ya que le endureció sus formas, siempre elegantes, y se sirvió de métodos que antes no había utilizado como la reiterada presentación de quejar formales. Antes de eso, en vez de entregar estas notas, que tenían un tono duro y severo, prefería entrevistarse tanto con Cordell Hull, como con el Subsecretario de Estado, Sumner Welles, y exponerles de primera mano documentos que hacían ver la situación desigual que se vivía en España. Por razones obvias las reuniones con el Presidente Roosevelt se dieron en menor medida.

Aunque finalmente la Ley de Neutralidad no se modificó un ápice, sí que tuvo distintos momentos en que aumentó la esperanza. Estos momentos coinciden estacionalmente. En ambas primaveras, las de 1937 y de 1938, no se sabe si el muro del embargo era más bajo, pero sin duda sí que se veía al menos más frágil. Los trágicos bombardeos de la aviación alemana sobre tierras vizcaínas en abril de 1937, empezaron a concienciar a una población que recibía mayoritariamente las informaciones e imágenes contra la Iglesia, sus edificios y sus miembros. La destrucción de Guernica abrió los ojos a la sociedad estadounidense, y movilizó en parte a los sectores más progresistas. Lamentablemente, para el trabajo de Fernando de los Ríos, este apoyo inicial era mínimo. La I Guerra Mundial provocó un sentimiento de miedo, a los norteamericanos que ni siquiera la gran distancia con un océano de por medio les hacía temer entrar en una nueva guerra.

Un año más tarde, otros bombardeos hicieron dudar sobre la necesidad de mantener la Ley de Neutralidad. En el mes de marzo de 1938, Barcelona sufría bombardeos contra la población civil. Estos hechos hicieron mella en la clase política, que por diversas iniciativas plantearon en el Congreso el fin de la Ley de Neutralidad. Pero tanto que estos políticos eran minoría en ambas cámaras, que se dieron campañas desde distintos sectores como el católico para frenar este tipo de iniciativas y que ese año había legislativas y que el Partido Demócrata no estaba dispuesto a perder el voto católico. Además, es interesante analizar el momento en que se dio esta iniciativa, apenas dos meses antes de la batalla del Ebro, que a la postre sería definitiva.

Para terminar, Fernando de los Ríos no obtuvo respuesta a todo el esfuerzo que puso por hacer ver a los estadounidenses que la Ley de Neutralidad perjudicaba al gobierno legítimo y democrático de España, mientras que alemanes e italianos iban de la mano con Franco. Por otro lado, los Estados Unidos tenían otros problemas más serios que ayudar a un gobierno tildado de comunista. Entre esos problemas estaba salir de la crisis provocada por el crack del 29 y en una sociedad aislacionista como la estadounidense, esto hacía que lo que le pasara a los españoles fuera algo secundario. 